\title{
Metastatic Spinal Cord Tumours
}

\author{
B. Acikgoz, MD, ${ }^{1}$ C. Akkurt, $M D,{ }^{2}$ A. Erbengi, MD,${ }^{3}$ V. Bertan, $M D,{ }^{3}$ \\ T. Özgen, MD, ${ }^{4}$ O. Özcan, $M^{4}$ \\ ${ }^{1}$ Instructor in Neurosurgery, Kahramanmaras State Hospital, ${ }^{2}$ Resident in Neuro- \\ surgery, ${ }^{3}$ Professor of Neurosurgery, ${ }^{4}$ Associate Professor of Neurosurgery, Hacet- \\ tepe University, School of Medicine, Ankara, Turkey.
}

\section{Summary}

In this report 84 patients who had surgical intervention for metastatic spinal cord tumours are presented. The primary tumours were mainly from lungs, breast or of haematological origin, and were commonest in the thoracic region. In all but 2 patients laminectomy was performed. Surgical decompression permitted diagnosis, and there was neurological improvement in nearly half of the patients.

Key words: Metastatic tumours; Spinal cord; Laminectomy; Anterior fusion.

In approximately $5 \%$ of patients with cancer, spinal cord metastasis occurs (Barron, 1959). The treatment of such metastases is still under discussion.

In this report 84 patients who had surgical intervention for metastatic spinal cord tumours are presented.

\section{Result}

Sixty four per cent were male and $36 \%$ female. In Figure 1 the age distribution is presented; $64 \%$ of the cases were over 40 years old.

On admission to the Neurosurgery Department $40 \%$ had severe pain. Nineteen per cent had urinary incontinence. Fourteen per cent had paraplegia, $16 \%$ had severe paraparesis and the other patients had moderate or mild paraparesis. Two patients were neurologically normal. In $13 \%$ the primary tumour was known preoperatively and these patients had been treated in other departments and underwent surgical decompression.

The neuroradiological changes are summarised in Table I. Plain radiographs revealed pathology in $47 \%$. The localisation of the tumours was: 43 in the thoracic region, 31 in the lumbar region and 10 in the cervical region. The operative findings are summarised in Table II. Twenty eight patients had a one-level laminectomy, 33\% a three-level laminectomy. In $96 \%$ epidural masses were found, and in $18 \%$ large tumours extending to the soft tissues were found. 


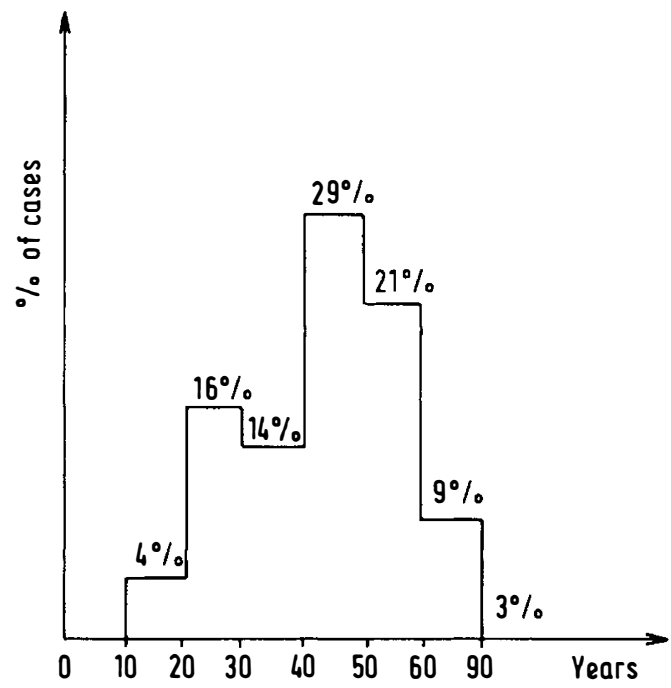

Figure 1 Distribution according to age.

Table I Neuroradiological findings

\begin{tabular}{llc}
\hline Findings & No. of Cases & ${ }^{\circ}$ \\
\hline $\begin{array}{l}\text { Plain X ray } \\
\text { Vertebral body }\end{array}$ & & \\
$\begin{array}{l}\text { depression fr. } \\
\text { Pedicle or/and }\end{array}$ & 25 & 29 \\
$\begin{array}{l}\text { lamina fracture } \\
\text { Myelography }\end{array}$ & 14 & 17 \\
$\quad$ Total block & & \\
Partial block & 65 & 77 \\
& 19 & 23 \\
\hline
\end{tabular}

Table II Operation findings

\begin{tabular}{lcr}
\hline Findings & No. of Cases \\
\hline & & \\
Anterior mass & 15 & 16 \\
Lateral mass & 27 & 32 \\
Posterior mass & 26 & 29 \\
One level & 24 & 28 \\
Two levels & 17 & 20 \\
Three levels & 28 & 33 \\
More than three & 15 & 17 \\
Extradural mass & 81 & 96 \\
Intradural mass & 3 & 4 \\
Extension to soft & & \\
$\quad$ tissues & 16 & 18 \\
Anterior fusion & 2 & 3 \\
\hline
\end{tabular}

The primary sites of tumours are presented in Table III. Five patients died in post-operative period. Six patients had neurological deterioration, 39\% were Grade 1, 33\% Grade 2, and 14\% had Grade 3 improvement. Grade 1 indicates slight improvement plus decrease in pain; Grade 2 indicates moderate improvement plus no pain; Grade 3 indicates full recovery. 
Table III Primary site of tumour

\begin{tabular}{llr}
\hline & No. of Cases & $\%$ \\
\hline Lung & 23 & 27 \\
Breast & 12 & 13 \\
Hematological & 18 & 21 \\
GIS & 8 & 9 \\
Prostate gl. & 8 & 9 \\
Unknown & 8 & 9 \\
Parotis gl. & 2 & 3 \\
Melanoma & 2 & 3 \\
Testis & 1 & 1.2 \\
Arachnoidal sarcoma & 1 & 1.2 \\
Surrenal gl. & 1 & 1.2 \\
\hline
\end{tabular}

* Including lymphoma, myeloma, leukemia

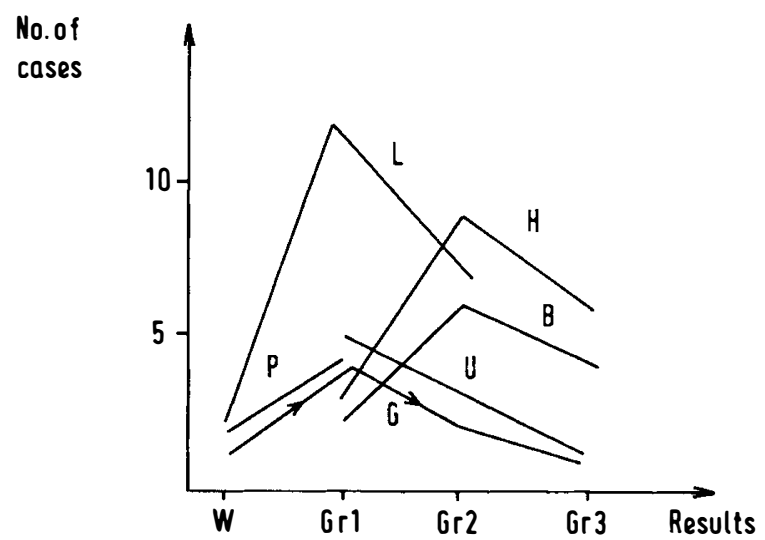

Figure 2 Neurological improvement according to tumour type. W: Worsened, H: Haematological tumours, B: Breast carcinomas, L: Lung carcinomas, U: Unknown originated metastatic tumour, P: Prostate carcinomas, G: Gastrointestinal system malignancies.

Table IV Additional Therapy following surgery (no. of Cases)

\begin{tabular}{lccc}
\hline & ChT & RT & ChT + RT \\
\hline Worsened & - & 1 & 1 \\
Gr 1 & 11 & 3 & 7 \\
Gr 2 & 7 & 9 & 12 \\
Gr 3 & 1 & 1 & 10 \\
\hline ChT: Chemotherapy & & \\
RT: Radiotherapy &
\end{tabular}

Figure 2 shows neurological improvement related to the primary tumour type and the result of therapy. Better results with haematological and breast carcinomas occurred in contrast to lung and prostate neoplasia. Table IV indicates those who had chemotherapy and or radiotherapy in addition to surgery. In Table $\mathrm{V}$ survival time is shown. The last examination dates were taken into consideration as the survival time. There were two exceptions. One patient who was treated for Hodgkin lymphoma and showed Grade 3 improvement, died 5 years later from heart failure, and another patient with a reticulum cell sarcoma Stage II died from intracranial metastases 2 years later. 
Table V Approximate survival time (in months)

\begin{tabular}{llcc}
\hline & Minimum & Average & Maximum \\
\hline Worsened & 1 & 2.5 & 6 \\
Gr 1 & 1 & 3.4 & 10 \\
Gr 2 & 1 & 6.2 & 24 \\
Gr 3 & 3 & 24 & 60 \\
\hline
\end{tabular}

\section{Discussion}

The incidence of metastatic spinal cord tumours among spinal cord tumours was reported to be 13 to $20 \%$ (Torma, 1957), in our series it was $11 \%$.

The management of metastatic spinal cord tumours is influenced by several factors. Nature of the primary tumour, site of the metastasis, general status of the patient, and the neurological status before treatment are the main factors (Barron, 1959; Constans, 1983; Barcena, 1984; Pedersen, 1984; Grem, 1985; Hartman, 1986).

The aim of surgery is to decompress the spinal cord and nerve roots (Constans, 1983). In cases during or after radiotherapy when neurological deterioration occurs surgery must be performed (Siegal, 1985). This occurred in $13 \%$ of the patients.

Metastatic cord tumours are pathologies which localise mainly in the thoracic regions (Constans, 1983) and cause neurological deterioration due to vertebral body collapse (Harrington, 1984; Siegal, 1985).

Decompressive laminectomy is the main method for surgical intervention (Sunderesan, 1985); usually 3 laminae. In $28 \%$ of our cases only one-level laminectomy was performed. In 2 patients anterior cervical body resection and fusion was performed. In the other 22 cases one-level laminectomy was done for tumours in the lower lumbar region; and one-level laminectomy was sufficient.

The type of primary tumour influenced the success of therapy.

The real survival time was not known because of the wide patient population from all parts of the country. Sixteen of our patients did not receive either chemotherapy or radiotherapy. These were the patients with post-operative neurological deterioration or showed Grade 1 improvement. Most of them left hospital refusing the entire treatment.

Decompressive laminectomy has two main disadvantages (Sunderesan, 1985; Siegal, 1985). It is not quite effective in anteriorly located tumours and may cause increased spinal instability. Recent reports advise anterior cord decompression plus spinal fusion with acrylic and metal instruments especially in anterior located tumours (Sunderesan, 1985; Harrington, 1984; Siegal, 1985; Overby, 1985). We had only 2 cases who had an anterior decompression and anterior bony fusion.

In conclusion we state that it is very difficult to have strict rules for the treatment of such patients, each must be handled individually. 
Barron KD, HiranoA, Araki S, et al. 1959 Experiences with metastatic neoplasms involving the spinal cord. Neurology 9: 91-106.

Constans JP, Divitirs E, DonZElli R, et al. 1983 Spinal metastasis with neurological manifestations. Fournal of Neurosurgery 59: 111-118.

GREM JL, BURGESS J, TRUMP DL 1985 Clinical features and natural history of intramedullary spinal cord metastasis. Cancer 56: 2305-2314.

HARRINGTON KD 1984 Anterior cord decompression and spinal stabilisation for patients with metastatic lesions of the spine. Fournal of Neurosurgery 61: 107-117.

HARRISON KM, MUSS HB, BALL MR, et al. 1984 Spinal cord compression in breast cancer. Cancer 55: 2839-2844.

HARTMAN R, HARTMAN S, GREEN N, 1986 Long-term survival following bony metastasis from basal cell carcinoma. Archives of Dermatology 122: 912-914.

OVERBY MC, ROTHMAN AS 1985 Anterohteral decompression for metastatic epidural spinal cord tumours. Results of a modified costotransversectomy approach. Fournal of Neurosurgery 63: 344-348.

Pedersen A G, Bach F, MelgaARd B 1984 Frequency diagnosis and prognosis of spinal cord compression in small cell bronchogenic carcinoma. Cancer 55: 1818-1822.

SIEGAL T, SIEGAL T 1985 Surgical decompression of anterior and posterior malignant epidural tumours compressing the spinal cord: A prospective study. Neurosurgery 17: 424-432.

SUNDERESAN N, GALILICH JH, LANE JM, et al. 1985 Treatment of neoplastic epidural cord compression by vertebral body resection and stabilisation. Fournal of Neurosurgery 63: 676684.

Sunderesan N, Bains M, MCCORMACK P 1985 Surgical treatment of spinal cord compression in patients with lung cancer. Neurosurgery 16: 350-356.

TORMA T 1957 Malignant tumours of the spine and spinal extradural space. Acta Surg Scand supplement 225: 1-176. 